\title{
Disentangling the Sources of Pro-social Behavior in the Workplace: A Field Experiment*
}

\author{
Mirco Tonin \\ University of Southampton \\ m.tonin@soton.ac.uk
}

\author{
Michael Vlassopoulos \\ University of Southampton \\ m.vlassopoulos@soton.ac.uk
}

August 2009

\begin{abstract}
This paper presents evidence from a field experiment, which aims to identify the two sources of workers' pro-social motivation that have been considered in the literature: action-oriented altruism and output-oriented altruism. To this end we employ an experimental design that first measures the level of effort exerted by student workers on a data entry task in an environment that elicits purely selfish behavior and we compare it to effort exerted in an environment that also induces action-oriented altruism. We then compare the latter to effort exerted in an environment where both types of altruistic preferences are elicited. We find that action-oriented altruism accounts for a significant increase in effort, while there is no additional impact due to outputoriented altruism. We also find significant gender-related differences in the treatment effect: women are very responsive to the treatment condition eliciting action-oriented altruism, while men's behavior is not affected by any of the treatments.
\end{abstract}

JEL Codes: C93, D64, J16

Keywords: Pro-social behavior, field experiment, effort, charitable donations

${ }^{*}$ We are grateful to Maryam Alriyami, Gloria Langat and Derya Tas for excellent research assistance, and to Alain Cohn, Robert Dur, Tore Ellingsen, Simon Gachter, Ethan Kaplan, Rob Sauer and seminar participants at the University of Southampton, CEU, IMEBE 2009, the CMPO Workshop on Public Services and Worker Motivation and the CESifo Workshop on Behavioral Public Economics for helpful comments and discussions. This research was funded by the Small Grants Scheme, School of Social Sciences, University of Southampton. 


\section{Introduction}

What motivates workers on their job? For certain type of workers, besides extrinsic rewards, an important drive is a concern towards the social cause pursued by the organization they work for, or a sense of altruism towards the welfare of a third party that is the recipient of the good or service being produced in their workplace. Such workers are willing to make labor donations, by providing on-the-job effort beyond what is contractually required of them. There is mounting empirical evidence that this type of labor donations are important in organizations engaging in the provision of education, health care, child-care, and social services as well as in charities and NGOs that advance all sorts of social missions. ${ }^{1}$

A recent burgeoning theoretical literature in economics recognizes the important role of workers' pro-social motivations and examines their implications for the design of incentive contracts, the selection of workers, the provision of effort and organizational design, see for instance, Besley and Ghatak (2005), Delfgaauw and Dur (2007, 2008), Dixit (2002), Francois (2000, 2007), Glazer (2004), Murdock (2002). Typically, two alternative views of altruism have been considered (a) Actionoriented altruism: the worker derives direct nonpecuniary benefits from the act of contributing to a cause she cares about ${ }^{2}$ and (b) Output-oriented altruism: the worker is concerned about the actual impact of her actions or the well-being of others. ${ }^{3}$ The two key implications of these approaches are that (1) An altruistic worker will provide more effort, and, (2) An altruistic worker requires less monetary compensation, see for instance Besley and Ghatak (2005).

In addition, papers that have taken the output-oriented approach, see for instance Francois $(2000,2007)$, have shown that this way of modelling pro-social preferences has implications for organizational design, as organizations without residual claimants may have an advantage in eliciting workers' altruistically motivated contributions to the organizations' output. On the contrary, this advantage does not arise with workers that display action-oriented altruism. Therefore, this distinction has important policy implications, for instance, regarding the debate over the privatization of public services delivery. The two approaches have also different implications for the motivation of workers in corporations that pursue social ends via corporate social responsibility (CSR) policies.

\footnotetext{
${ }^{1}$ Most notable is the recent evidence in the paper by Gregg et al. (2009) who study the incidence of donated labor in the U.K., measured by unpaid overtime, and find that it is more likely to occur in the not-for-profit sector than in the for-profit sector.

${ }^{2}$ There may be various psychological underpinnings for this, including the receipt of social recognition that improves self-respect or pride (Benabou and Tirole 2006, Ellingsen and Johannesson 2008), which has been the focus of some recent experimental studies (Ariely et al. 2009).

${ }^{3}$ These two conceptualizations of workers' altruism are the logical counterparts of 'warm glow' and 'pure altruism', the two motives that in economics have been associated with charitable giving and the private provision of public goods, see Andreoni (1989, 1990).
} 
In particular, the exact nature of workers' pro-social motivation matters for the design of the CSR policy (e.g. should the fraction of the firm's profits that is donated to the social cause be linked to workers' productivity or not).

While these two approaches have proved to be useful in deriving theoretical insights as to the implications of workers' pro-social preferences, no attempt to quantify and discriminate the importance of the two using non-experimental data has been made, in part because appropriate field data that would allow for sound econometric analysis are difficult to come by. In this paper we report findings from a controlled experiment which is a first, to our knowledge, attempt to disentangle and quantify the two sources of intrinsic motivation. An important aspect of our design is that we observe subjects providing real effort in a natural work environment, thus heeding Levitt and List (2007) who argue that pro-social behavior observed in the lab may not translate into behavior in the field. A related point is made by Della Vigna (2009) in a recent review of the literature on economics and psychology, who points out that "the research on social preferences displays more imbalance between laboratory and field" compared to research on other topics and calls for "more papers linking the findings in the laboratory $[\ldots]$ to the evidence in the field" (pg 341). Similar type of labor market field experiments using student workers have been recently used to evaluate how various behavioral considerations, such as, reciprocity and peer effects operate in labor markets (Falk and Ichino, 2006; Gneezy and List, 2006; Hennig-Schmidt et al., 2008).

We hired university students through email announcements to perform a short-term computer data entry job on two separate occasions (one hour each). Using a short term job has the advantage of removing career concern aspects or repeated game strategies that may represent a confounding factor for the interpretation of the results (Bandiera et al., 2005). On the first occasion we paid all students $£ 10$ plus a performance bonus based on their performance. On the second occasion, we randomized students into three different groups. For the first group the second occasion was identical to the first one. This baseline condition acts as our control, as it accounts for any change in productivity due to experience, learning and so on. For the two other groups, we implemented two treatments aimed at eliciting, respectively, action-oriented effort and effort that is induced by both types of altruistic preferences. More specifically, in treatment A, we adapted the methodology developed by Crumpler and Grossman (2008), which aimed at isolating and measuring warm-glow giving in a laboratory setting, using a dictator game where the recipient was a charity. In that paper, subjects were given a monetary endowment and were asked how much of that they would want to allocate to a charity when the contribution of the subject crowded out the contribution of the experimenter such that the charity always received a fixed amount. They found that subjects 
donated on average $20 \%$ of their endowment, which provides evidence of the strength of the warm glow motivation for charitable giving. In our setting, we are interested in measuring the strength of the action-oriented motivation for making labor donations, so in this treatment we told subjects that besides their personal compensation, which remained the same as in the first occasion, their effort could contribute to a charity of their choice, but their contribution would perfectly crowd out our contribution so that the total amount the charity received was fixed at $£ 15$. Given the nature of the donation any additional effort that the students might provide in this treatment, relative to the baseline treatment, can be solely attributed to action-oriented intrinsic motivation. In treatment B, we told subjects that besides their personal compensation, which remained the same as in the first occasion, their effort could contribute to a charity of their choice with no crowding out taking place, so that the total donation that the charity received depended on their effort. In this treatment, both sources of pro-social behavior are elicited. Therefore, any additional effort that we observe in this treatment relative to treatment A can be attributed solely to output-oriented altruism.

We found that effort is positively affected by an environment that induces action-oriented altruism, while there is no additional impact due to output-oriented altruism. Interestingly, we found significant gender-related differences in the treatment effect. In particular, our results suggest that women are very responsive to the treatment condition eliciting action-oriented altruism, increasing their productivity between the two sessions by an additional 14\% compared to women in the control group, while they do not display any additional increase in effort due to output-oriented altruism. On the other hand, for male subjects, we found no statistically significant differences in productivity changes between the control and any of the treatment groups. This unresponsiveness suggests that pro-social preferences are less relevant for men than for female workers in our sample. Our results are consistent with those obtained in studies that have examined experimentally differences in social preferences across genders. ${ }^{4}$

The rest of the paper is organized as follows: the next section presents the experimental design. Section 3 discusses the conceptual framework we use and derives the behavioral predictions. Section 4 presents the results of the study and section 5 offers some concluding remarks.

\footnotetext{
${ }^{4}$ See Camerer (2003) and Croson and Gneezy (2009) for an overview of the experimental evidence of gender differences in social preferences.
} 


\section{Experimental Design}

\subsection{Recruitment and Task}

The experiment was conducted with undergraduate students recruited through email announcements at the University of Southampton in the fall term of 2008. The job ad was asking for students interested in assisting with data entry for a research project in economics. The announcement stated that no prior experience was needed other than basic typing and some familiarity with Microsoft Excel and that interested students should be able to work for a period of 2 hours on two separate occasions over a four-week period. The email also indicated that compensation would include a $£ 10$ fixed-fee for each session plus a performance bonus. Interested students were asked to respond indicating their availability, and selection among respondents was based on this information. In total we recruited 71 students of diverse academic backgrounds - Computer Science, Biology, Social Sciences and Engineering - excluding Economics. It is worth noting that students were unaware ex-ante that they were participating in an experiment.

The task consisted of typing data contained in input-output tables that the student received in a booklet into an Excel Worksheet. ${ }^{5}$ Each table consisted of 48 randomly generated 3-digit numbers (2 decimals) that always added up to 100. Each table in the booklet and the worksheet is identified by a date (e.g. Jan 1953) and students had to enter each table frame in the corresponding worksheet. For each table, students were told not to enter the last column and row, as these were automatically calculated by Excel, but were asked to check that the numerical values calculated by Excel for the last column and row corresponded to the ones on the booklet and that the value in the bottom right cell equalled 100. The worksheet also contained a counter which tracked the number of completed tables, the student's compensation and the donation amount when applicable. ${ }^{6}$ This particular data entry task was chosen such that performance is perfectly measurable (number of table entries), and did not allow for cooperation or teamwork, as each participant worked separately without knowing what other participants were doing or even how many other participants were involved. This has the advantage of removing possible confounding factors related to peer pressure. The task was performed in a standard university office on a desktop computer.

We employed 3 research assistants to give instructions and supervise student workers (each student was supervised by the same assistant on both occasions). The research assistants after greeting the student and introducing the task left the office so that during working time the student

\footnotetext{
${ }^{5}$ See the attached Instructions sheet given to subjects for a more detailed description of the task.

${ }^{6} \mathrm{~A}$ screen-shot of the worksheet used for data entry is included in the Appendix.
} 
was not monitored. After one hour, the assistant came back and counted the number of entries. At the end of the second occasion, payments were arranged and the student was asked to fill out a short questionnaire. For each session, students received the pre-announced fixed wage of £10, plus a performance bonus of $10 \mathrm{p}$ per table entry. Their total compensation was on average $£ 13$ per session.

\subsection{Treatments}

Each one of the treatments that was part of our design involved the students performing the task in two separate occasions, 60 minutes on each session. The two sessions were approximately 2 weeks apart. Employing a within-subject design allows us to control for individual differences in typing ability that might be present. We observe no attrition between sessions in our sample as all of the students who were recruited turned up in both sessions. On the first occasion, all students were paid on the basis described above, so that compensation depended on the amount of work performed. There was no mention in the first occasion that a charitable donation might be introduced later. On the second occasion students were randomized into three treatments ${ }^{7}$. Some underwent the first treatment, which we call the Baseline treatment and serves as our control. In this condition students were paid on the exact same basis as in the first session. The difference in output between sessions 1 and 2 produced by those involved in this treatment is going to serve the benchmark against which we are going to compare performance in the other treatments.

In Treatment A, students were offered the same personal compensation as in the Baseline Treatment. Moreover, students were told that due to the funding of the project, in addition to their personal compensation we were going to make a lump-sum donation to a charity of the student's choice (£15). ${ }^{8}$ It was explained to them that part of the lump-sum donation will be made on their behalf based on their performance: for each table the charity received $30 \mathrm{p}$ on their behalf, while the rest would be supplemented by us so that the charity received a total of $£ 15$.

Finally, in Treatment B, students were offered the same piece rate as in the Baseline Treatment and, in addition, were told that a donation will be made to their preferred charity on their behalf based on their performance: for each table they typed the charity would receive $30 \mathrm{p}$ on their behalf. To ensure that each subject in Treatments A and B valued the cause to which the donation

\footnotetext{
${ }^{7}$ We check whether the distribution of observable characteristics is the same across treatments using a nonparametric contingency table Pearson chi-square test. The gender composition is not significantly different across treatments (p-value: 0.639), as is citizenship (p-value: 0.997), year of birth (p-value: 0.665 ), course of study (p-value: 0.525 ), year of study (p-value: 0.430 ).

${ }^{8}$ The list of charities used in the experiment is included in the Appendix.
} 
is directed we allowed participants to choose the donation recipient not only among a list of charities with diverse missions, but also by indicating an alternative charity. ${ }^{9} 10$ The option of not making any contribution was also present, in which case the money would remain in the research fund, but nobody exercised it. Compared to the Baseline, in the two treatments the job is then characterized by a pro-social dimension, represented by the charitable donation. Notice that in both treatments it is the student's choice that determines whether a donation is made at all as well as to which charitable cause the donation is contributing to.

Comparison of effort obtained across the three treatments allows us to assess the relative strength of the two alternative sources of pro-social motivation in the workplace. In particular, comparing the changes in effort we observe in the two sessions between Treatment A and the Baseline allows us to detect any effort due to action-oriented altruism, while the changes in effort we observe in the two sessions between Treatment B and Treatment A allows us to detect any effort due to output-oriented altruism. In the following section we present a simple framework that makes these predictions regarding workers' behavior in the three treatments more precise.

To summarize, our experimental design shuts down alternative channels which might cause workers to act pro-socially in the workplace, such as the expectation of future labor market rewards (career concerns) or peer pressure. Also, we believe that reciprocity (gift exchange) toward the employer related to the personal compensation can be ruled out for several reasons. First, on average these students were making the standard undergraduate RA hourly wage and therefore it is unlikely that their compensation would be received as very generous. Second, the use of piece rate compensation means that any additional effort is remunerated and thus reduces the possibility that workers use effort as a way to reciprocate toward the employer. Finally, as personal compensation is the same across control and treatment groups what we measure when comparing productivity across them is effort induced by either type of altruism, over and above effort induced by feelings of reciprocity toward the employer, if any.

\subsection{Conceptual Framework}

In this section we present a simple specification of a worker's utility function and derive optimal effort in three working environments that correspond to the three treatments that are part of our design. This framework helps us formulate the main behavioral predictions that we then evaluate

\footnotetext{
${ }^{9}$ Four subjects indicated an unlisted charity of choice.

${ }^{10}$ To ensure the credibility of the donation, subjects were also asked to indicate whether they wanted to receive a thank you email from the charity. Slightly more than half of the subjects opted to receive a note.
} 
in our field study and helps with the interpretation of the results.

Suppose that a worker's preferences are represented by the following quasi-linear utility function:

$$
U(y, e, g)=y-c(e)+\gamma(e)+\phi(g)
$$

where $y$ is income, $e$ is effort supplied and $g$ is a public good the worker cares about. The cost of exerting effort is captured by the convex cost function, $c(\cdot)$. The utility function in (1) embeds both a concern for material compensation as well as the two sources of pro-social motivation that are of interest here. Action-oriented altruism is captured by the concave function, $\gamma(\cdot)$, which represents the enjoyment the worker receives when effort contributes to the production of a good or service she considers socially worthwhile. Output-oriented altruism is captured by the the last term in the utility function, the concave function $\phi(\cdot)$, which implies that the worker is concerned about the total quantity of a public good, $g$, that is provided. ${ }^{11}$ Notice that the worker's effort may directly contribute to the amount of public good, that is, $g=g(e ; \varepsilon)$, where $\varepsilon$ represents a vector of other inputs in the production of the public good.

Suppose that the worker's income is $y=k+e p$, where $p$ is a piece rate the worker receives for each unit of output/effort, and $k$ represents income from other sources plus possibly a lump-sum payment related to the job. We examine effort provision in three different settings.

First, the baseline case, where the worker's effort is unrelated to the production of the public good so both sources of pro-social behavior are absent. Then equilibrium effort is given by:

$$
e^{*} \text { s.t. } c^{\prime}\left(e^{*}\right)=p \text {, }
$$

namely, where the marginal cost of effort is equated to the marginal private return of effort. This case corresponds to the Baseline Treatment in our experimental design.

Second, the action-oriented case, where worker's effort takes place in an environment that is associated with the production of the public good but where effort does not directly affect the quantity of the public good. Then equilibrium effort is given by:

$$
\text { ê s.t. } c^{\prime}(\hat{e})=p+\gamma^{\prime}(\hat{e}),
$$

\footnotetext{
${ }^{11}$ In the interest of clarity we present here the separable case. However, what follows does not rely on the separability of the two effects. It holds under a more general specification where the two effects are not additively separable $U(y, e, g)=y-c(e)+\pi(e, g)$, where $\frac{\partial \pi}{\partial e}>0, \frac{\partial \pi}{\partial g}>0$ and $\frac{d^{2} \pi}{d e^{2}}<0$.
} 
where the marginal return of effort is increased by the fact that the worker enjoys the act of contributing to the production of the public good. Note that the properties of $c(\cdot)$ and $\gamma(\cdot)$ imply that $\hat{e} \geq e^{*}$. This case corresponds to Treatment $\mathrm{A}$ in our experimental design, as in that context workers' effort contributes to a charitable cause but has no impact on the total amount that gets transferred. We summarize the first main behavioral prediction:

Prediction 1 Any difference in the amount of effort supplied in Treatment A relative to the Baseline Treatment, $\hat{e}-e^{*}$, is due to the worker's action-oriented altruism.

Third, the complete case, where worker's effort takes place in an environment that is associated with the production of the public good and is directly linked to the amount of the public good produced, so both kinds of pro-social motivations are potentially induced. Then equilibrium effort is given by:

$$
\tilde{e} \text { s.t. } c^{\prime}(\tilde{e})=p+\gamma^{\prime}(\tilde{e})+\phi^{\prime}[g(\tilde{e} ; \varepsilon)] \frac{\partial g(\tilde{e} ; \varepsilon)}{\partial e}
$$

where the marginal return of effort is augmented by its impact on public good provision. Note that $\phi^{\prime}(\cdot) \geq 0$ implies that $\tilde{e} \geq \hat{e}$. This case corresponds to Treatment B in our experimental design, as in that context workers' effort contributes to a charitable cause and it does not lead to crowding out of the experimenter's contribution.

We can now state the second main behavioral prediction of this framework:

Prediction 2 Any difference in the amount of effort supplied in Treatment B relative to Treatment $A, \tilde{e}-\hat{e}$, is due to the worker's output-oriented altruism.

This simple framework provides us with some predictions regarding how we should expect that a worker will respond to each of these settings that involve a monetary compensation and induce different combinations of altruistic motivations (action and output oriented). In the next section we present the results of the study.

\section{Results}

We are going to evaluate both behavioral predictions by assessing the change in productivity between the two sessions across the different treatments. In particular, we look at the percentage 
change in output measured by the total number of completed tables in each session. Table 1 provides descriptive statistics and Figure 1 displays the kernel density estimates of the distribution of productivity changes across treatments. The first thing to notice is that in all treatments it appears that there is an increase in average productivity between the first and the second session. Despite a relatively simple task, it is likely that some learning is taking place: in the second session students are more familiar with the environment and the requirements of the job. This underlines the importance of having a baseline treatment to control for all factors affecting productivity changes between the two sessions other than compensation. Moreover, subjects in the treatment groups appear to raise productivity by more (15\%) than those in the baseline $(12 \%)$. We formally assess whether this difference is statistically significant using a one-tailed Mann-Whitney (M-W) test and a one-tailed Kolmogorov-Smirnov (K-S) test (see Table 2). ${ }^{12}$ The difference between control and treatment $\mathrm{A}$ and the difference between control and treatment $\mathrm{B}$ is statistically significant at the $p<0.1$ level, in most of the cases, while the difference between treatment A and B is insignificant.

The data in Table 1 also suggest that there are significant gender differences in the treatment effect. $^{13}$ This is also evident when one inspects the distribution of productivity changes for each gender separately (Figures 2 and 3). In particular, women appear to be more responsive to the treatment conditions, as they raise productivity by $21 \%$ in treatment $\mathrm{A}$ and $19 \%$ in treatment $\mathrm{B}$ as compared to $12 \%$ for women in the baseline condition and these differences between treatments and the baseline are significant at the $p<0.05$ level, while the difference between treatment $\mathrm{A}$ and $\mathrm{B}$ is insignificant. On the other hand, for men each comparison yields insignificant differences. Notice that for the control group the average values for the level of productivity and its change across sessions are identical between men and women. This suggests that the differential response between genders is not due to different learning across genders, but rather due to the treatments. We also tested whether the distributions differ significantly across gender. For the control this is not the case $(\mathrm{M}-\mathrm{W}$ two-tailed p-value $=0.967, \mathrm{~K}-\mathrm{S}$ two-tailed $\mathrm{p}$-value $=1.000)$. This confirms that there is no gender-specific element in the task in itself. On the other hand, the distribution for the treatment groups are significantly different across gender $(\mathrm{M}-\mathrm{W}$ two-tailed $\mathrm{p}$-value $=0.012, \mathrm{~K}-\mathrm{S}$ two-tailed p-value $=0.085)$, confirming a differential response to treatments. ${ }^{14}$

\footnotetext{
${ }^{12}$ The alternative hypothesis for the tests presented in table 2 is that average productivity in the treatment condition is greater than that in the baseline.

${ }^{13}$ No differences have emerged with regards to other dimensions for which there is enough variation in the data, e.g. previous work experience, occupational expectations (for profit vs non-profit sector), course of study (natural sciences and engineering vs social sciences and education), donation to charity in the last 12 months, volunteering activity in the last 12 months.

${ }^{14}$ In light of the previous result that the two treatments are not significantly different, we pooled treatments A and $\mathrm{B}$ to improve the power of the test.
} 
To summarize, the distribution of productivity changes displays a significant shift to the right for both treatments compared to the control group, while there is no difference between treatments. This implies that action-oriented altruism is motivating subjects to work harder, while there is no evidence of output-oriented altruism. Looking at the data disaggregated by gender, we find that the effect is very strong for women, while it is insignificant for men. We now proceed to quantify the strength of this motivation, both non-parametrically and through regression analysis. One way to estimate the shift in the distributions between the two treatments and the control group nonparametrically is to use the Hodges-Lehmann median difference. For females, this equals 0.104, implying a $10.4 \%$ additional increase in productivity compared to the control group due to actionoriented altruism, and is significant at the $5 \%$ level.

Table 2 - Statistical Test Results

\begin{tabular}{|c|c|c|c|}
\hline & All & Men & Women \\
\hline \multicolumn{4}{|c|}{ Control vs Treatment A } \\
\hline Mann-Whitney test & 0.066 & 0.379 & 0.028 \\
\hline Kolmogorov-Smirnov & 0.044 & 0.349 & 0.030 \\
\hline \multicolumn{4}{|c|}{ Control vs Treatment B } \\
\hline Mann-Whitney test & 0.084 & 0.418 & 0.041 \\
\hline Kolmogorov-Smirnov & 0.115 & 0.679 & 0.040 \\
\hline \multicolumn{4}{|c|}{ Treatment A vs Treatment B } \\
\hline Mann-Whitney test & 0.482 & 0.478 & 0.413 \\
\hline Kolmogorov-Smirnov & 0.429 & 0.380 & 0.438 \\
\hline
\end{tabular}

One-tailed p-values are reported.

The magnitude of this effect is in line with the one obtained in a regression setting. Due to the presence of several outliers (see the box-whiskers graphs, Figure 4), we use a quantile (median) regression approach. The following equation is estimated

$$
y_{i}=\beta_{0}+\beta_{1} D A_{i}+\beta_{2} D O_{i}+\varepsilon_{i},
$$

where $y_{i}$ is the percentage change in productivity between the first and the second sessions for subject $i, D O$ is a dummy equal to 1 if the subject is in treatment $\mathrm{B}$, while $D A$ is a dummy equal to 1 if the subject has been treated. Thus, $\beta_{2}$ measures the increase in productivity due to output oriented altruism, while $\beta_{1}$ measures the increase in productivity due to action-oriented altruism. Consistently with the non-parametric tests, for the whole sample the coefficient of the dummy 
variables $D O$ is close to zero and highly insignificant, while the coefficient of $D A$ is significant both statistically and economically, indicating an $8 \%$ increase in productivity compared to the control group due to action-oriented altruism. Also, the analysis disaggregated by gender confirms the picture already drawn by the non-parametric tests: in the case of women productivity is increasing by $14 \%$ due to action-oriented altruism, while for men the coefficient of $D A$ is close to zero and highly insignificant. Very similar results (not reported) are obtained when using M estimation (iteratively reweighted least squares ${ }^{15}$ ).

Table 3 - Median Regression

\begin{tabular}{cccc}
\hline \hline & All & Men & Women \\
\hline$D A$ & $.078^{* *}$ & .027 & $.139^{* *}$ \\
& $(.039)$ & $(.092)$ & $(.060)$ \\
$D O$ & -.007 & -.061 & -.034 \\
& $(.035)$ & $(.085)$ & $(.056)$ \\
Constant & $.088^{* * *}$ & .111 & $.088^{* *}$ \\
& $(.029)$ & $(.073)$ & $(.043)$ \\
\hline \multirow{2}{*}{$N}$. & 71 & 33 & 38 \\
\hline \hline
\end{tabular}

Standard errors in parentheses.

*** [**] $(*)$ denote significance at $1,[5],(10) \%$ level.

\section{Concluding Remarks}

Experimental methods have enhanced our understanding of how various behavioral notions, such as fairness, trust, reciprocity, loss-aversion and peer effects operate in labor markets (Falk and Gaechter, 2008). Recently there has been an increased interest in understanding the motivating factors behind workers' pro-social behavior in workplace settings. This paper contributes to this literature by performing a first, to our knowledge, field experiment which attempts to disentangle and measure the two alternative sources of workers' pro-social motivation. Our results underline the importance of action-oriented intrinsic motivation in the workplace, as it accounts for an increase in effort provision that is both statistically and economically significant. On the other hand, we do not find any evidence of output-oriented motivation.

One might think that another motivation that may be responsible for the students' response

\footnotetext{
${ }^{15}$ In particular, we use the STATA implementation, rreg, which uses Huber weights at the beginning of the computation and biweights successively.
} 
to the treatments is a form of indirect reciprocity towards the employer, driven by the fact that the employer has acted pro-socially by offering charitable donations as part of the compensation package. We believe that if such an effect is present, it is of second order compared to the direct effect of the donation appealing to the worker's altruistic motivation toward the charity itself. To see this note that a worker who is not altruistic would not derive any additional utility from the donation made by the employer and therefore would not have any reason to reciprocate toward the employer. Thus, any such type of indirect reciprocity is conditional on the worker being altruistically motivated, implying that its effect on worker's effort provision is of second order compared to the direct effect of the worker's own altruistic motivation, which this study aims to identify. Also, as explained above with a piece rate compensation scheme in place, working harder is a very blunt instrument to reciprocate toward the employer.

Another important finding of this paper is that there are considerable gender differences in pro-social motivation. In particular, in our sample, pro-social behavior is displayed by women, but not by men. This finding is consistent with the literature on gender differences in social preferences. In particular, Eckel and Grossman (1998) report results from dictator experiments in conditions of anonymity that indicate that women are more generous than men: women donate on average about twice what men donate. Andreoni and Vesterlund (2001) also study gender differences in a dictator game where the price of giving varies and find more nuanced results: women are more generous when giving is expensive, and as giving becomes cheaper men are more altruistic. Mellström and Johannesson (2008) carry out a field experiment to examine whether offering blood donors a monetary compensation might crowd out their intrinsic motivation for giving and find this to be the case for women but not for men.

The finding of a gender difference in pro-social behavior in a workplace setting may have important implications for women's economic outcomes, as if women are more likely to enter occupations and sectors with characteristics that engender pro-social behavior, e.g. health, education and social care, and require less monetary compensation then gender differences in pro-social motivation would help explain the observed occupational segregation by gender, that accounts for a substantial portion of the overall gender earnings gap (Gunderson, 1989).

An important related issue is that of accounting for the sorting of workers that takes place in real labor market settings. The importance of sorting when measuring social preferences experimentally has been demonstrated by Lazear et al. (2006). Accounting for self-selection will not only lead to the detection of the treatment effect for those workers who choose to sort into care-related jobs, but also the identification of the characteristics that determine selection into sectors that engender 
pro-social behavior. These issues are the subject of ongoing research.

\section{References}

[1] Andreoni, J. (1990): "Giving with Impure Altruism: Applications to Charity and Ricardian Equivalence," Journal of Political Economy, 97(6), 1447-58.

[2] Andreoni, J. (1990): "Impure Altruism and Donations to Public Goods: A Theory of WarmGlow Giving," Economic Journal, 100(401), 464-477.

[3] Andreoni, J. and Vesterlund, L. (2001): "Which is the Fair Sex? Gender Differences in Altruism," Quarterly Journal of Economics, 116(1), 293-312.

[4] Ariely, J., Bracha, A., and Meier, S. (2009): "Doing Good or Doing Well? Image Motivation and Monetary Incentives in Behaving Prosocially," American Economic Review, forthcoming.

[5] Camerer, C. F. (2003): Behavioral Game Theory: Experiments in Strategic Interaction, Princeton, NJ: Princeton University Press.

[6] Croson, R. and Gneezy, U. (2009): "Gender Differences in Preferences," Journal of Economic Literature, 47(2): 448-74.

[7] Bandiera, O., Barankay, I., and Rasul, I. (2005) "Social Preferences and the Response to Incentives: Evidence from Personnel Data," Quarterly Journal of Economics, 120(3), 917-962.

[8] Benabou, R. and Tirole, J. (2006): "Incentives and Prosocial Behaviour," American Economic Review, 96(5), 1652-1678.

[9] Besley, T., and Ghatak, M. (2005): "Competition and Incentives with Motivated Agents," American Economic Review, 95(3), 616-636.

[10] Besley, T., and Ghatak, M. (2007): "Retailing Public Goods: The Economics of Corporate Social Responsibility," Journal of Public Economics, 91(9), 1645-1663.

[11] Crumpler, H., and Grossman, P. (2008): "An Experimental Test of Warm Glow Giving," Journal of Public Economics, 92(5-6), 1011-1021.

[12] Delfgaauw, J., and Dur, R. (2007): "Signaling and Screening of Workers' Motivation," Journal of Economic Behaviour and Organizations, 62(4), 605-624. 
[13] Delfgaauw, J., and R. Dur (2008): "Incentives and Workers' Motivation in the Public Sector," Economic Journal, 118, 171-191.

[14] DellaVigna, S. (2009): "Psychology and Economics: Evidence from the Field," Journal of Economic Literature, 47(2), 315-372.

[15] Dixit, A. (2002): "Incentives and Organizations in the Public Sector: An Interpretative Review," Journal of Human Resources, 37(4), 696-727.

[16] Eckel, C. C. and Grossman, P. (1998): "Are Women Less Selfish than Men? Evidence from Dictator Experiments," Economic Journal, 108, 726-35.

[17] Ellingsen, T., and Johannesson, M. (2008): "Pride and Prejudice: The Human Side of Incentive Theory," American Economic Review, 98(3), 990-1008.

[18] Falk, A., and Gaechter, S. (2008): "Experimental Labor Economics," in Steven Durlauf and Lawrence E. Blume (eds): New Palgrave Dictionary of Economics. Basingstoke: Palgrave Macmillan.

[19] Falk, A., and Ichino, A. (2006): "Clean Evidence on Peer Effects," Journal of Labor Economics, $24,39-57$.

[20] Francois, P. (2000): “Public Service Motivation' as an Argument for Government Provision,” Journal of Public Economics, 78(3), 275-299.

[21] Francois, P. (2007): "Making a Difference," RAND Journal of Economics, 38(3), 714-732.

[22] Glazer, A. (2004): “Motivating Devoted Workers," International Journal of Industrial Organization, 22(3), 427-440.

[23] Gneezy, U., and J. List (2006): "Putting Behavioral Economics to Work. Testing for Gift Exchange in Labor Markets Using Field Experiments," Econometrica, 74, 1365-1384.

[24] Gregg, P., Grout, P., Smith, S., Ratcliffe, S. and Windmeijer, F. (2009): "How Important is Pro-Social Behaviour in the Delivery of Public Services?," CMPO Working Paper No. 08/197.

[25] Gunderson, M. (1989): "Male-Female Wage Differentials and Policy Responses," Journal of Economic Literature, 27, 46-72.

[26] Hennig-Schmidt, H., B. Rockenbach, and A. Sadrieh (2008): "In Search of Workers' Real Effort Reciprocity - A Field and a Laboratory Experiment," Journal of the European Economic Association, forthcoming. 
[27] Lazear, E., U. Malmendier and R. Weber (2006): "Sorting in Experiments with Application to Social Preferences," NBER Working Paper Series, \#12041.

[28] Levitt, S., and List, J. (2007): "What Do Laboratory Experiments Tell us About the Real World?," Journal of Economic Perspectives, 42(2).

[29] Mellström, C., and Johannesson, M. (2008): "Crowding Out in Blood Donation: Was Titmuss Right?," Journal of the European Economic Association, 6(4): 845-863.

[30] Murdock, K. (2002): "Intrinsic Motivation and Optimal Incentive Contracts," RAND Journal of Economics, 33(4), 650-671. 


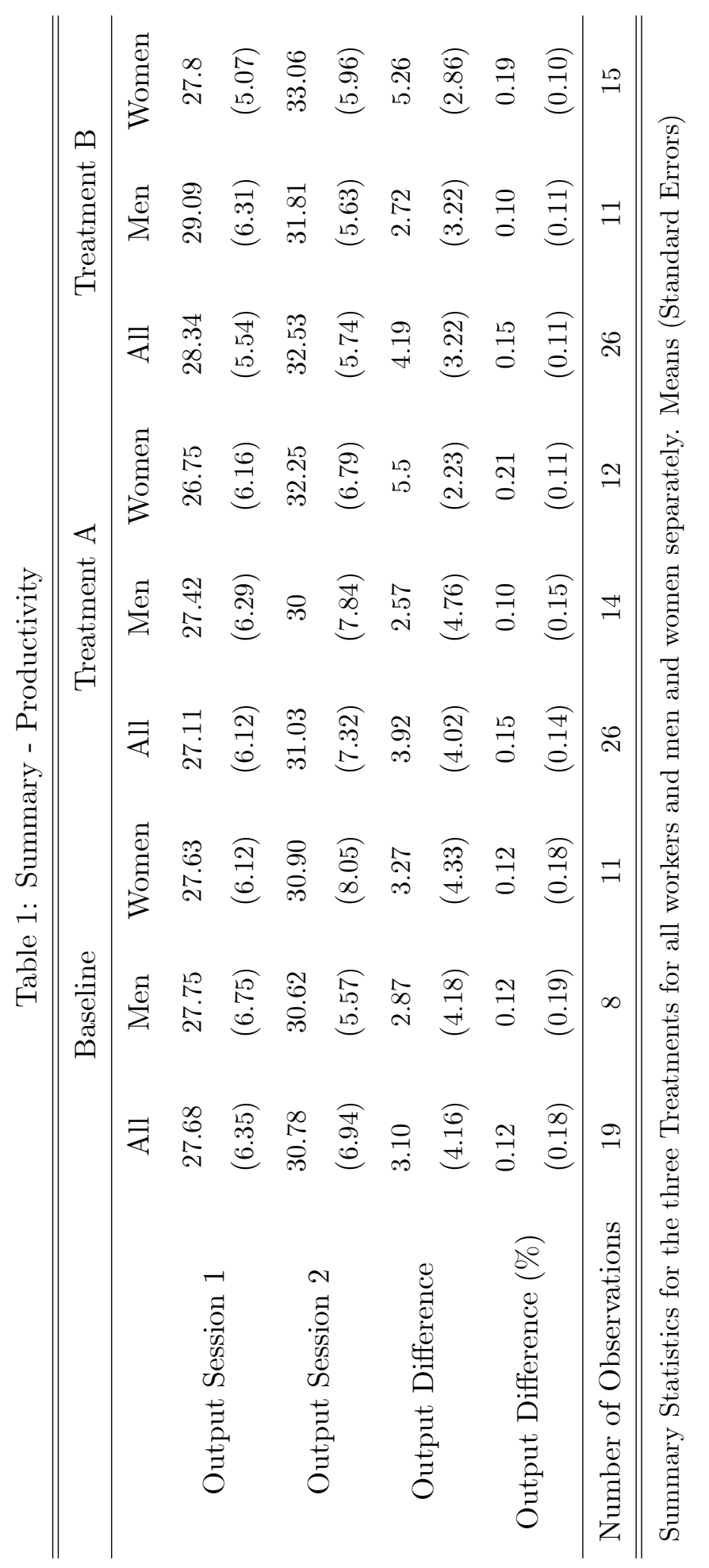


Figure 1

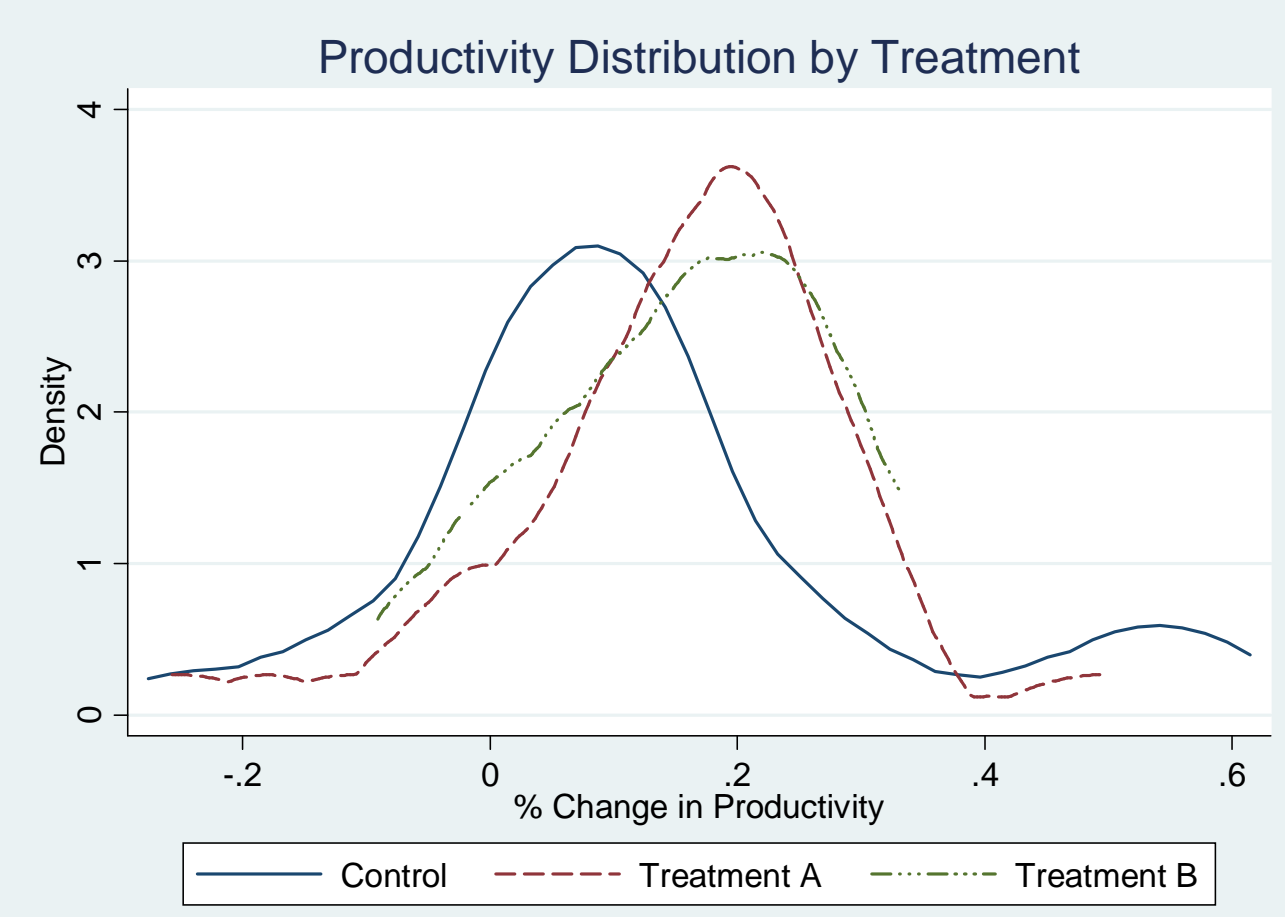

Figure 2

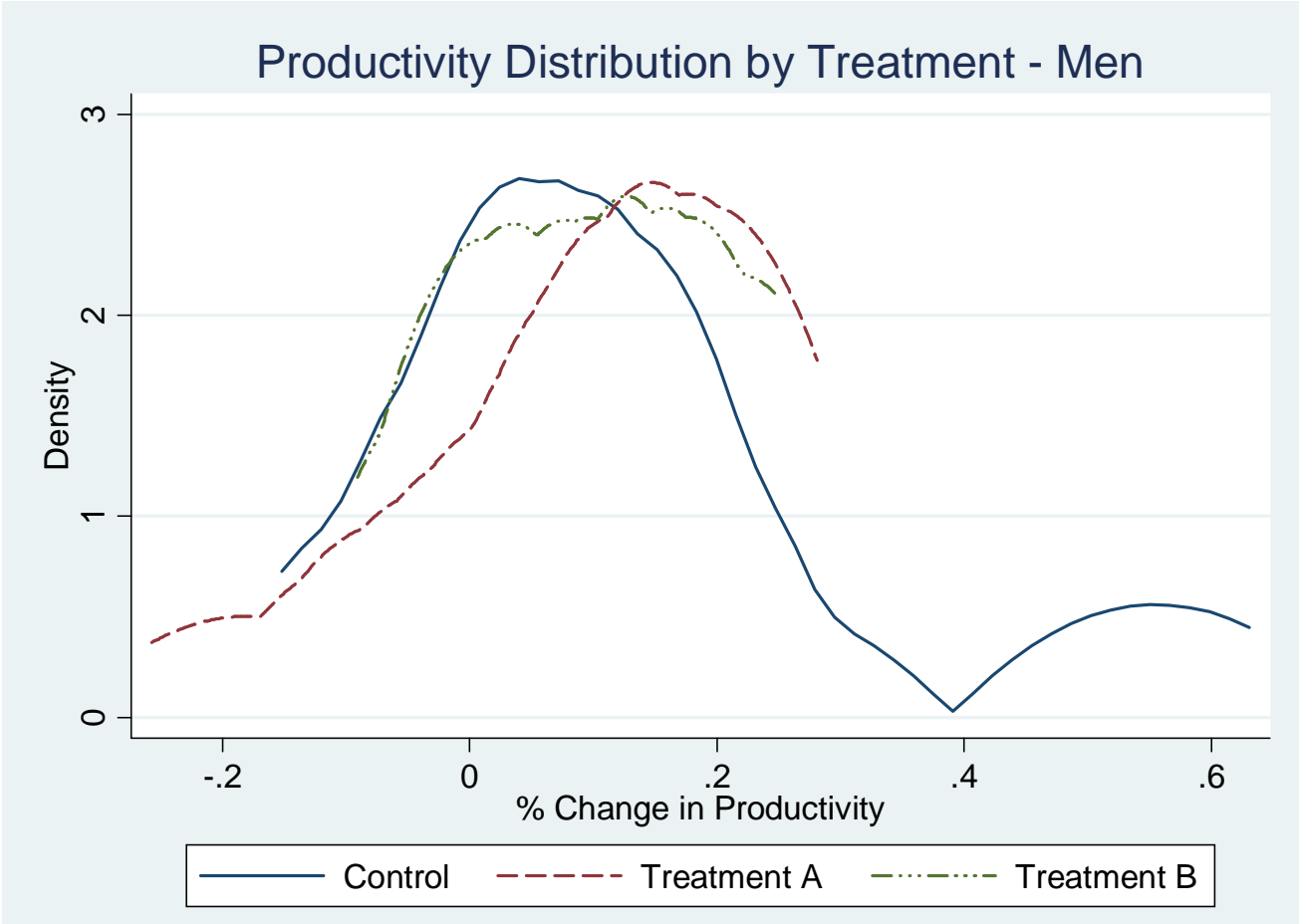


Figure 3

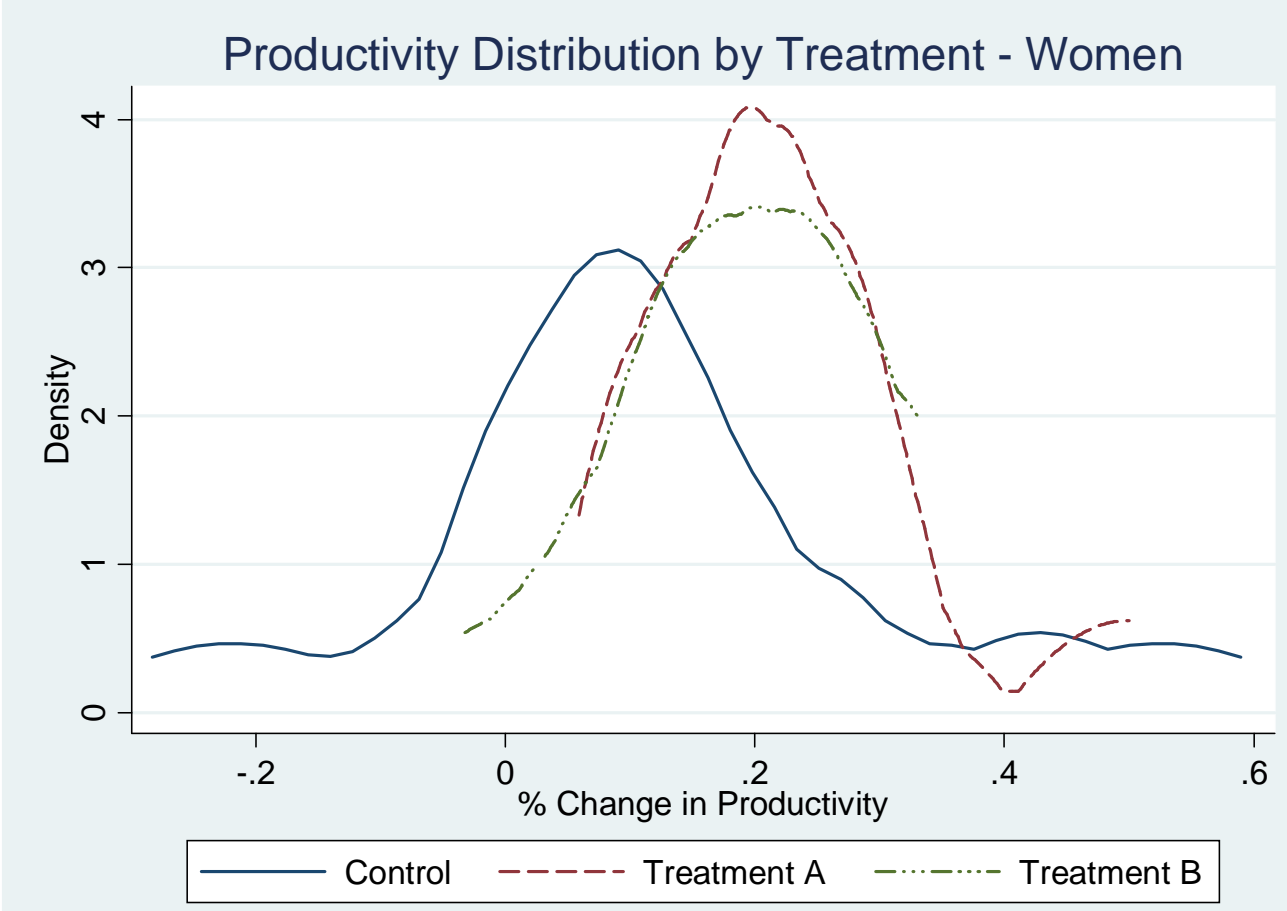

Figure 4

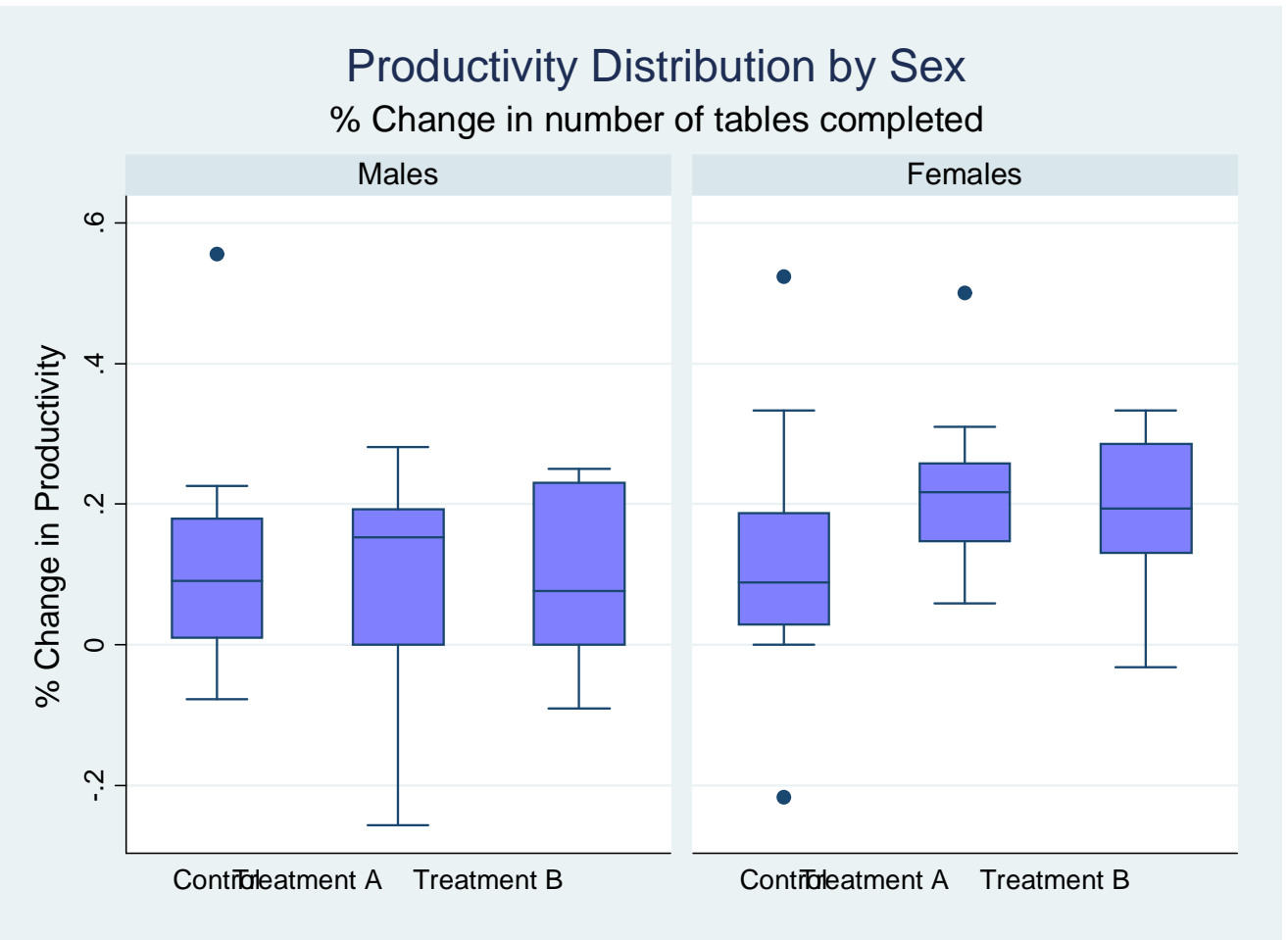




\section{Instructions First Round}

Please read carefully the following instructions, detailing how the job should be performed and the structure of your compensation. If after reading the instructions you have any questions, please ask the Assistant.

\section{Job description}

The task consists of entering the numerical tables contained in the booklet that you were given into the Excel file that is currently open on the screen in front of you.

Each table in the booklet is identified by a date (e.g. Jan 1953) and the data should be entered in the table frame in the Excel worksheet with the same date. After you enter all the numerical values for the table on one page, move to the next page and to the next Excel Worksheet. To make identifying activated Worksheets easier, once you start entering numbers in a table the corresponding Worksheet Tab will turn red.

For each table, you should NOT enter the last column and row, as these are automatically calculated by Excel. Once you finish entering the data for a given table, you should check that the numerical values calculated by Excel for the last column and row correspond to the ones on the booklet. If that is not the case, it means that you made a mistake in entering the data and you should recheck the table and correct the mistakes. Also notice that the value in the cell on the crossing between the last column and row should always equal " 100 ".

Your work will last for 60 minutes. After that time, the Assistant will come back and check your work.

If you would like to stop at anytime before the end of the work period or you need to contact the Assistant, please dial the indicated contact number.

\section{Compensation}

For this session you will be paid $£ 10$, plus 10 p for each table you enter. For example, if in the following 60 minutes you enter 10 tables, you will earn $£ 11(£ 10+10 * 10 p)$, if you enter 20 tables you will earn $£ 12(£ 10+20 * 10$ p) and so on.

Your compensation will be calculated at the end of the second session, at which time a transfer to your bank account will be arranged. 


\section{Instructions Second Round, Second Treatment}

\section{Job description}

The task is the same as in the previous session.

Your work will last for 60 minutes. After that time, the Assistant will come back, check your work and arrange your compensation.

If you would like to stop at anytime before the end of the work period or you need to contact the Assistant, please dial the indicated contact number.

\section{Compensation}

For this session you will be paid $£ 10$, plus 10 p for each table you enter. For example, if in the following 60 minutes you enter 10 tables, you will earn $£ 11(£ 10+10 * 10 p)$, if you enter 20 tables you will earn $£ 12(£ 10+20 * 10 p)$ and so on.

Your compensation will be calculated at the end of the session, added to what you earned in the first session and a transfer to your bank account will be arranged.

Due to the funding of the project, in addition to your personal compensation, by filling out the attached donation form, you can designate a charity of your choice that will receive a donation of $£ 15$. Of this $£ 15$, for each table you complete 30 p will be donated on your behalf, while the rest will be supplemented by us, so that the charity receives $£ 15$ regardless. For instance, if you enter 10 tables then $10 * 30 \mathrm{p}=£ 3$ will be donated on your behalf and we will contribute $£ 15-£ 3=£ 12$, so that the charity receives a total of $£ 15$. Notice that your personal compensation is completely unaffected by the donation and that the charity will receive neither more nor less than $£ 15$. 


\section{Instructions Second Round, Third Treatment}

\section{Job description}

The task is the same as in the previous session.

Your work will last for 60 minutes. After that time, the Assistant will come back, check your work and arrange your compensation.

If you would like to stop at anytime before the end of the work period or you need to contact the Assistant, please dial the indicated contact number.

\section{Compensation}

For this session you will be paid $£ 10$, plus 10 p for each table you enter. For example, if in the following 60 minutes you enter 10 tables, you will earn $£ 11(£ 10+10 * 10 p)$, if you enter 20 tables you will earn $£ 12(£ 10+20 * 10 p)$ and so on.

Your compensation will be calculated at the end of the session, added to what you earned in the first session and a transfer to your bank account will be arranged.

Due to the funding of the project, in addition to your personal compensation, by filling out the attached donation form, you can designate a charity of your choice that will receive on your behalf a donation of 30p for each table you complete. For instance, if you complete 10 tables, the charity you chose will receive $10 * 30 \mathrm{p}=£ 3$. Notice that your personal compensation is completely unaffected by the donation. 


\section{DONATION FORM}

Please choose the charity you wish to contribute by putting an $\mathrm{X}$ to the box next to your choice.

\begin{tabular}{|c|c|}
\hline NAME & DESCRIPTION \\
\hline Amnesty International & $\begin{array}{l}\text { Campaigns to uphold human rights across the } \\
\text { world. }\end{array}$ \\
\hline British Red Cross & $\begin{array}{l}\text { Offers emergency response, health and social } \\
\text { care, first aid and refugee services. }\end{array}$ \\
\hline Cancer Research UK & $\begin{array}{l}\text { Works toward improving our understanding of } \\
\text { cancer and develop better ways to prevent, } \\
\text { diagnose and treat the disease. }\end{array}$ \\
\hline Greenpeace UK & $\begin{array}{l}\text { Defends the natural world and promotes peace } \\
\text { by investigating, exposing and confronting } \\
\text { environmental abuse, and championing } \\
\text { environmentally responsible solutions. }\end{array}$ \\
\hline Help the Aged & $\begin{array}{l}\text { Committed to addressing the issues that matter } \\
\text { to older people; Provides healthcare, gives } \\
\text { older people a voice and responds to } \\
\text { emergencies in the developing world. }\end{array}$ \\
\hline $\begin{array}{c}\text { MSF } \\
\text { (Medecins Sans } \\
\text { Frontiers\Doctors Without } \\
\text { Borders) } \\
\end{array}$ & $\begin{array}{l}\text { Committed to providing medical aid wherever } \\
\text { it is needed, regardless of race, religion, } \\
\text { politics or gender }\end{array}$ \\
\hline $\begin{array}{c}\text { NSPCC } \\
\text { (National Society for the } \\
\text { Prevention of Cruelty to } \\
\text { Children) }\end{array}$ & $\begin{array}{l}\text { Specialises in child protection and the } \\
\text { prevention of cruelty to children }\end{array}$ \\
\hline Oxfam GB & $\begin{array}{l}\text { A development, relief, and campaigning } \\
\text { organisation that works with others to find } \\
\text { lasting solutions to poverty and suffering } \\
\text { around the world }\end{array}$ \\
\hline $\begin{array}{c}\text { RSPCA } \\
\text { (Royal Society for the } \\
\text { Prevention of Cruelty to } \\
\text { Animals) }\end{array}$ & $\begin{array}{l}\text { Works to reduce the harmful impact of human } \\
\text { activities on animals through education, } \\
\text { campaigning and the application of ethics, } \\
\text { science and law }\end{array}$ \\
\hline \multicolumn{2}{|l|}{ Other (Please specify) } \\
\hline I do not wish to contribute & \\
\hline
\end{tabular}

Do you want to receive a thank you email from the charity? yes [ ] no [ ]

Name:

Signature: 


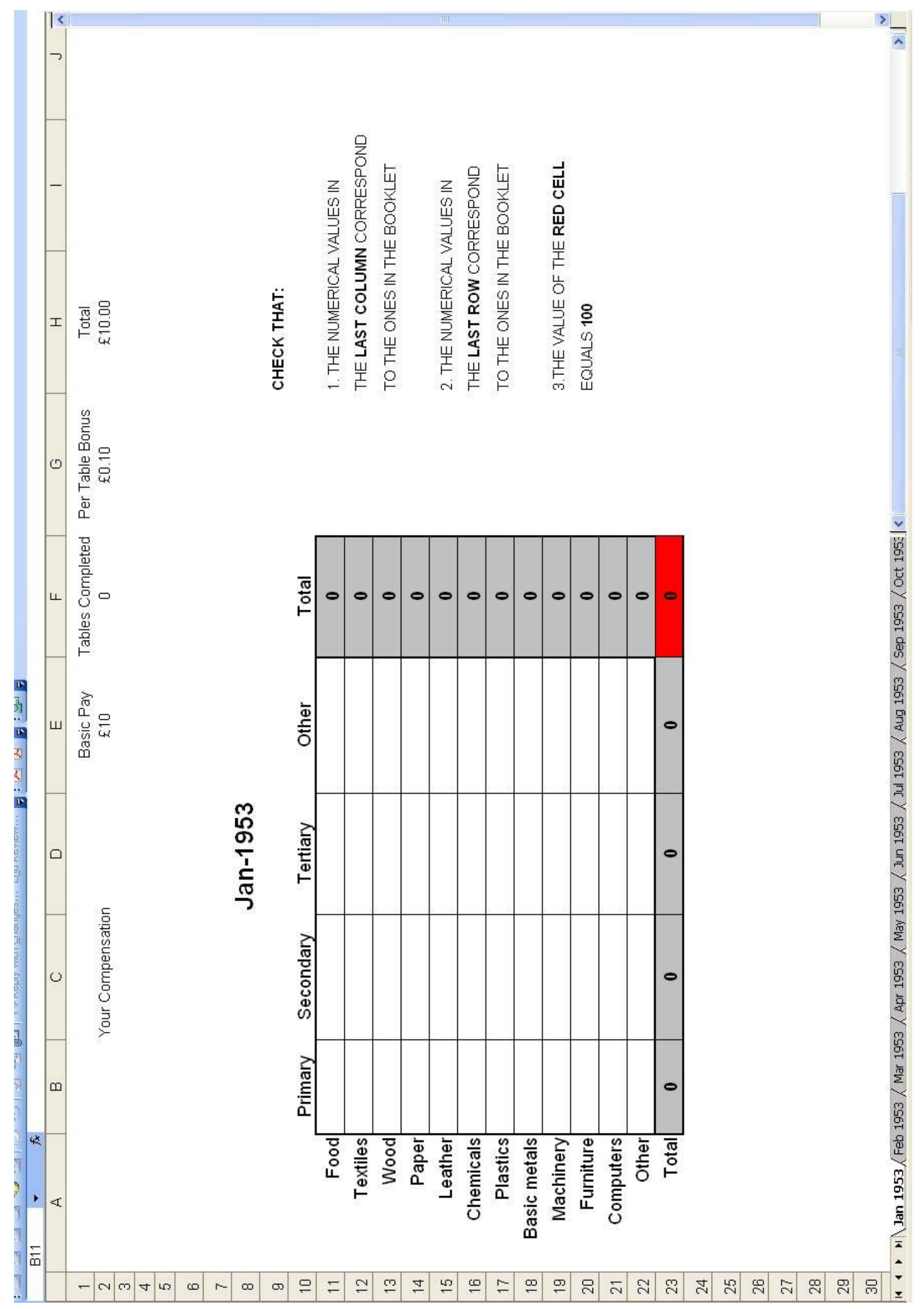

